'deaths' of materials. Online platforms for sharing corrosion data are badly needed. Access to a large volume and variety of corrosion information that researchers could probe with data mining and modelling tools would improve forecasts of corrosion failures and anticorrosion designs.

\section{COMPLEX PROCESSES}

The biggest challenge in corrosion research is predicting accurately how materials will degrade in a given environment ${ }^{2}$. It requires full knowledge of all relevant factors and their interactions. Yet precise models for mechanisms are lacking. Forecasting problems is impossible without historical data about materials failures under various conditions. And field performances cannot be judged in laboratories when environmental parameters are unknown.

Corrosion data are hard to collect. Damage may take years or decades to accumulate and any project tracks only a handful of contributing factors. Data sets need to be combined. For example, early studies of marine corrosion (occuring, for instance, on oil-drilling platforms) were unreliable because they considered only physiochemical processes (those involving $\mathrm{pH}$, dissolved oxygen and temperature) and not the effects of organisms living in seawater. The inclusion of genomic data has now improved the models.

Corrosion depends on local conditions. Steel structures that last for decades in dry parts of inland China fail within months in humid and salty coastal areas of southeast Asia. Protective polymer coatings that work for years at northern latitudes can degrade in weeks near the Equator, where heat and greater doses of ultraviolet radiation break chemical bonds more quickly. Inferring general corrosion knowledge - such as how particular steels are affected by humidity, salt or air pollution - requires combining studies from many diverse environments. One worldwide survey of weathering steel, for example, reviewed exposure test results for up to 22 years from 108 sites in 22 countries $^{3}$.

With global trade increasing, the oil and gas, construction, car, electronics and other industries have called for corrosion data to be shared between countries to ensure the quality and safety of their products. Millions of cars worldwide have been recalled in the past few years owing to unforeseen corrosion problems arising in destination countries. China's 2013 'Belt and Road' initiative, which promotes industrial ties with countries along the Silk Road economic belt between China and the West, raises unprecedented challenges. Rapid corrosion assessment, materials selection and design will be needed as billiondollar construction, transport, energy and telecommunications projects begin in Asia, Africa and Europe.

Advanced materials present entirely

new corrosion problems. For example, the electrochemical stabilities of noble metals such as platinum and gold fall sharply as their dimensions decrease to nanometre scales. Corrosion of platinum nanoparticles remains a roadblock limiting the lifetime of platinum-based catalysts for fuel cells.

Corrosion scientists have been slower than their materials-science peers to recognize the need for data sharing. Several large materials-data repositories built by US governmental agencies under the auspices of the MGI house basic physical, chemical and microstructure data for materials, but not corrosion data. Yet none of the advanced materials promised by

"Forecasting problems is impossible without historical data about material failures."

the MGI will be practical without considering their environmental stability and durability.

\section{DATA REPOSITORIES}

Open data infrastructures should be set up to house corrosion data in various countries, industries and applications. By using the same standardized formats for data and metadata, the data can be connected and eventually amount to a global system, possibly linked to the MGI.

Governments should take the lead. For example, the Chinese government has invested nearly 200 million yuan (US\$30 million) since 2006 on a platform for sharing corrosion data from 30 field-testing stations covering standard materials in environments (air, soil and water) typical of different parts of the country. Other nations, industries and interest groups should establish similar data infrastructures for corrosion in other regions and sectors.

Efforts need to be coordinated to collect corrosion data that are relevant to urgent or emerging challenges, such as alternative energy and nanotechnology. For instance, the US Department of Energy has partnered with the MGI to build materials data repositories to help to speed up the development of alternative clean-energy sources.

Funding agencies should incentivize the sharing of corrosion data about advanced materials and emerging technologies, for example, by demanding it in research grants and supporting the costs of publishing in open-access journals. Corrosionscience societies should learn from general materials-science societies (such as Materials Research Society, the Minerals, Metals \& Materials Society and ASM International) and convene experts to establish datasharing best practices and guidelines.

Industry involvement can be encouraged through partnerships with academia. Companies would save research and development costs in return for contributing data to repositories. Because corrosion concerns maintenance and safety rather than industrial competition, businesses should be willing to share such data. Data consortia can be formed to identify common topics of priority and jointly develop benchmark solutions, just as industrial standards are agreed.

More-powerful tools need to be developed for data capturing, management, mining, modelling and simulation - the integration of which we term corrosion big data and informatics ${ }^{4}$. Advanced monitoring technologies require 'big data' analytics. For instance, robots (known as 'smart pigs') carrying hundreds of sensors deployed to inspect the walls of pipelines can collect 1 terabyte of data in one run. Highly accurate corrosion simulations could partially or completely replace the time-consuming, environmentally unfriendly, complicated and expensive experimental corrosion tests. For example, quantum chemical simulations are heavily used to evaluate the molecular structures and electronic properties of corrosion inhibitors ${ }^{5}$.

If corrosion data is shared, everyone will benefit from the greater understanding that results.

Xiaogang $\mathbf{L i}$ is professor at the Key Laboratory for Corrosion and Protection of the Ministry of Education, Institute of Advanced Materials \& Technology, University of Science and Technology Beijing, Beijing, China, and is at the Ningbo Institute of Material Technology \& Engineering, Chinese Academy of Sciences, Ningbo, Zhejiang, China. Dawei Zhang, Zhiyong Liu, Zhong Li, Cuiwei Du and Chaofang Dong are at the Key Laboratory for Corrosion and Protection of the Ministry of Education, Institute of Advanced Materials \& Technology, University of Science and Technology Beijing, Beijing, China. e-mail:dzhang@ustb.edu.cn

1. Koch, G., Brongers, M., Thompson, N., Virmani, Y. \& Payer, J. Corrosion Cost and Preventive Strategies in the United States (NACE International, 2002).

2. Duquette, D. et al. Research Opportunities in Corrosion Science and Engineering (National Academies Press, 2011).

3. Morcillo, M., Chico, B., Díaz, I., Cano, H. \& de la Fuente, D. Corrosion Science 77, 6-24 (2013).

4. Li, X. Informatics for Materials Corrosion and Protection: The Fundamentals and Applications of the Materials Genome Initiative in Corrosion and Protection (Chinese Chemical Industry Press, 2014) (in Chinese).

5. Taylor, C., Chandra, A., Vera, J. \& Sridhar, N Faraday Discussions 180, 459-477 (2015).

\section{CORRECTION}

The Comment article 'Einstein was no lone genius' (M. Janssen and J. Renn Nature 527, 298-300; 2015) wrongly stated the dates during which Albert Einstein studied at the Swiss Federal Polytechnical School in Zurich. He was there between 1896 and 1900 . 